\title{
Candace Slater
}

University of California, Berkeley, USA

LS: Quais os conceitos mais centrais e fecundos na obra crítica e historiográfica de Antonio Candido?

A maioria das pessoas com quem tenho a honra de dividir estas páginas são brasileiros natos. Todas têm atrás de si carreiras notáveis, dedicadas à análise literária e cultural e próximas de Antonio Candido - isto é, tanto do autor de uma longa série de obras decisivas como também da figura central na vida intelectual do país. Em vista disso, creio que pode ser útil, à guisa de prefácio a meus comentários, explicar que ouvi o nome de Antonio Candido pela primeira vez quando era uma incipiente aluna de graduação da Universidade de Stanford, na década de 1970, ou seja, numa época em que o Brasil costumava ser visto, nos Estados Unidos, como um curioso apêndice da América Latina.

Minha carreira universitária começou numa era em que muitos acadêmicos seguiam enamorados do New Criticism, do estudo de textos em si e por si mesmos. Adentrar o campo da literatura latino-americana num momento em que o assim chamado boom ainda conservava seu ímpeto significava penetrar num mundo em que, de chofre, as obras literárias não podiam ser compreendidas fora de um contexto social e histórico. Os primeiros livros de Antonio Candido com que eu viria a travar contato - Tese e antítese e Literatura e sociedade aderiam, em termos gerais, a essa visão mais ampla e socialmente engajada da literatura. Contudo, eles também se destacavam em aspectos imediatamente flagrantes.

Sobretudo, os livros sublinhavam uma série de elos complexos entre a literatura e outras espécies de relação social. Diferiam, assim, de um bom número de estudos que traçavam vínculos fáceis entre texto e contexto. Nos dois livros, as obras literárias emergiam como uma espécie poderosa de mediação - intricadas, multifacetadas e vitais. Esse caráter intricado tornava impossível reduzir os textos a esquemas ideológicos óbvios e dados de antemão. Ao contrário de muita crítica marxista de mão pesada em voga naqueles dias, as análises de 
Antonio Candido eram finamente calibradas e infalivelmente sutis. Uma coisa dificilmente produzia uma outra por via causal direta; as palavras pareciam capazes de guardar sentidos ocultos justamente quando pareciam mais transparentes. Os gêneros literários eram ao mesmo tempo fixos e fluidos, assumindo novas formas às mãos de autores que, por vezes, bem podiam não ter completa consciência do poder dessas formas.

Além disso, tanto Tese e antítese como Literatura e sociedade sugeriam que a literatura e a crítica literária deviam ser entendidas, em algum nível, como empreendimentos morais. Uma vez que existiam num mundo de interesses econômicos e classistas em competição, as obras de arte necessariamente assumiam alguma posição diante do estado das coisas. Essa atitude moral não precisava se traduzir numa posição política declarada. Ela bem podia, aliás, revelar um feixe de contradições que, por sua vez, sinalizavam pontos de penetração profícuos em textos que podiam ser julgados tanto pelos critérios literários costumeiros (vocabulário, ponto de vista, etc) como por descompassos entre o que seus autores diziam explicitamente e o que as obras em pauta pareciam de fato mostrar.

Por fim, num momento caracterizado por sentimentos revolucionários muitas vezes efusivos, a escrita de Antonio Candido destacava-se por sua contenção. Muito de sua força provinha de uma espécie de understatement que refletia um ceticismo inabalável, mas pródigo de simpatia humana. Além disso, por mais que a justiça e a injustiça fossem forças reais em ação na obra submetida à investigação crítica, sua presença era muitas vezes esquiva e difícil de retraçar. Essa dificuldade sublinhava o fato de que a literatura era vista como fundamentalmente cinética: seu convite perpétuo à reinterpretação fadava-a ao movimento perpétuo. Ao mesmo tempo em que eram sempre postos no papel por indivíduos ávidos por expressar uma visão pessoal, os textos literários eram também inevitavelmente propriedade de um grupo específico, situado num momento histórico preciso. A tarefa do crítico, portanto, consistia em determinar o lugar de um certo bloco de palavras tanto numa dada página como nos recessos e recantos de uma existência vivida em comum.

\section{LS: Neste sentido, que obra ou que ensaio the parece exemplar?}

Minha seleção de Os parceiros do rio Bonito como exemplo do conjunto da produção intelectual de Antonio Candido reflete, sem dúvida, meu próprio interesse de longa data em formas "folclóricas" como as histórias de peregrinação, os relatos amazônicos e nordestinos sobre o "mundo encantado" e a literatura de cordel. Contudo, por mais que seja parcialmente pessoal, minha seleção também remete à inestimável perspectiva comparatista que se evidencia nessa única incursão de Antonio Candido nas ciências sociais.

Num ensaio ponderado sobre as implicações de Parceiros para a disciplina da Sociologia no Brasil, o professor Luiz Antonio C. Santos faz notar, em ter- 
mos convincentes, o "compromisso ético-político de denúncia" e a "opção clara pela simplicidade" do livro, que contrastam com o jargão profissional. Após realçar a habilidade com a qual o estudo transita de um corpo de teoria sociológica para outro, sempre que essa "transgressão" promete iluminar o objeto de estudo, ele chama a atenção para uma determinada "postura ética diante do mundo acadêmico" que se exprime na aversão de Antonio Candido ao autoelogio. Muito embora tenham em mira os cientistas sociais, essas observações também despertam o leitor para uma consideração mais ampla de Parceiros como precursor e como compêndio de qualidades que marcam a obra mais explicitamente literária de Antonio Candido.

Vale a pena enfatizar a ligação existente entre o livro e o corpo mais amplo da obra. Antes de mais nada, Os parceiros do rio Bonito estuda a mudança em seu sentido mais amplo. Análise em profundidade de um certo segmento da sociedade caipira no interior do estado de São Paulo, o livro é também um retrato vívido de uma sociedade mais ampla em plena transição. Muito embora documente as práticas diárias de um certo grupo de pessoas, seu verdadeiro tema é o Brasil do fim da década de 1940 e do começo da década de 1950 - de uma época em que mudanças sociais maciças, associadas à urbanização, estavam rapidamente pondo de lado um modo de vida consagrado pelos tempos no interior do país. A linguagem do livro é claramente acadêmica, mas ainda assim seu autor sabe evocar o drama de uma comunidade chamada a testemunhar seu próprio desaparecimento. A profunda ambivalência inerente às evocações caipiras, mais e mais idealizadas, de um passado claramente imperfeito encontra eco nas análises que Antonio Candido dedicou a autores surpreendidos por transformações que muitas vezes desafiam aqueles mesmos valores que eles se propunham a enaltecer.

Muito embora não toque em questões literárias de modo mais seguido, Parceiros não deixa dúvida quanto à visão das formas expressivas como forças sociais. Inicialmente concebido como tese de doutorado sobre as letras que acompanhavam o cururu - a "dança cantada" característica do interior de São Paulo -, o livro que Antonio Candido viria a publicar uma década mais tarde é sobretudo uma meditação sobre a transformação de todo um modo de vida. $\mathrm{O}$ que poderia facilmente não ter sido mais que um livro sobre folclore, apinhado de referências a índices de motivos e esquemas de rima, converteu-se num estudo de um mundo em fluxo. Na medida em que focaliza o lugar da cultura e da sociabilidade humana num mundo tantas vezes reduzido a "enunciados políticos" ou a considerações estreitamente econômicas, o livro se converte num argumento convincente em prol da análise literária e cultural. O uso de dados quantitativos em Parceiros (descrições detalhadas do consumo de calorias pelos caipiras, por exemplo) só faz enfatizar a necessidade do quadro mais amplo em que essa informação se insere.

Repetidas vezes, Antonio Candido transforma descrições instrumentais de práticas econômicas cotidianas em observações nuançadas de trocas sociais. 
Como resultado, a verdadeira dança de que trata o livro é menos o cururu e mais as piruetas verbais que os indivíduos devem executar a fim de conservar a dignidade, ao mesmo tempo em que matam a fome. Conforme Antonio Candido nota com precisão lírica, "a comida é sempre considerada indigna por quem oferece e de raro paladar por quem aceita". Essa coreografia cuidadosa prossegue à medida que o anfitrião caipira lamenta a parcimônia da refeição e o hóspede responde, exaltando sua abundância. "Qualquer infração desses padrões acarreta ressentimentos profundos e duradouros", observa Antonio Candido, sugerindo assim a que ponto algo de aparentemente tão concreto quanto devorar um frango assado é sempre, também, um ato profundamente simbólico.

A percepção lúcida que o autor tem das ficções necessárias à vida social tende a impregnar observações factuais com um elemento de poesia inesperada. A profunda consciência dessas ficções que há em Parceiros não impede relances de identificação apaixonada com as pessoas que figuram em suas páginas. A breve evocação de Pio Lourenço Corrêa ("admirável tipo de fazendeiro paulista, culto e reto") vibra com uma admiração genuína, que a economia verbal torna mais intensa. "A sua conversa era uma lição constante; a sua experiência, imensa; a sua memória, prodigiosa", diz o autor numa única frase resplandecente, cuja compressão sugere uma familiaridade respeitosa, fruto de longas horas de conversa. A descrição de tantos outros informantes, gente o mais das vezes analfabeta, como "homens da mais perfeita cortesia, capazes de se esquecerem de si mesmos em benefício do próximo" vem igualmente confirmar este ponto. A decisão de fechar o livro com um apêndice contendo três histórias narradas por um dos entrevistados, Nhô Roque, sugere que, por mais fielmente que Antonio Candido orquestre a experiência desses homens, a última palavra é sempre deles.

Registro de primeira mão da transformação de um interior antes isolado, Parceiros não por isso deixa de recordar outras tantas análises mais diretamente literárias de Antonio Candido em sua preocupação com a questão mais ampla da justiça e da injustiça. Por mais que permaneça estritamente voltado para seu tema imediato, o livro não por isso deixa de formular uma posição política que transcende grupos específicos e momentos históricos determinados. Sem nada de passadista ou sentimental, o autor insiste na enormidade da perda cultural em curso. De modo que não deixa de lembrar os retirantes de Graciliano Ramos em Vidas secas, os parceiros de Antonio Candido, voltando-se cada vez mais para a cidade, são forçados a abandonar alguma coisa que, áspera como era, lhes era também peculiar.

A força poética das observações mais factuais do livro estende-se a seu título. À primeira vista, nada poderia soar tão chão quanto Os parceiros do rio Bonito. "Parceiros" designa uma forma de propriedade da terra amplamente documentada pelos cientistas sociais; "rio Bonito" é um topônimo dos mais comuns. Contudo, as muitas camadas das observações subsequentes convidam o leitor familiarizado com o texto a encontrar no título mais coisas do que de início 
saltam à vista. Desta perspectiva mais lírica, os parceiros tornam-se não apenas coproprietários de parcelas de terra agrícola, mas também parceiros de um legado comum - ainda que de modo desigual - a todos os brasileiros. Do mesmo modo, o rio Bonito, tão pedestre, passa a sugerir aqueles enormes rios míticos no coração do continente largamente desconhecido que os mapas coloniais desenhavam. É esse Brasil - ao mesmo tempo lar de pessoas reais e fabuloso ato de imaginação - que rebrilha em muitas das meticulosas dissecções de textos literários às mãos de Antonio Candido. As longas horas que passou observando pessoas reais nutriram sua percepção de personagens literários; a complexidade que ele reconheceu em informantes de carne e osso permitirá que ele aborde uma vasta galeria de figuras inventadas como similarmente humanas.

\section{LS: A perspectiva de Antonio Candido tem vigência no cenário atual?}

Tantos aspectos do que Antonio Candido representa em termos de perspectiva crítica foram absorvidos pelo mainstream da reflexão sobre a literatura brasileira, tantos de seus argumentos são hoje ponto de partida mesmo para críticos que saem a campo para refutar esta ou aquela de suas opiniões, que se torna difícil responder em termos significativos à pergunta sobre a relevância de sua obra para um presente em vias de globalização. Seria relativamente fácil produzir uma lista de afirmações e atitudes (referências em Parceiros a "mentalidades primitivas" ou "culturas rústicas", por exemplo) que hoje nos pareceriam obsoletas ou seriamente equivocadas. De resto, pode-se bem imaginar Antonio Candido dedicando-se alegremente a compilar uma tal lista para uso desta nossa era eletrônica.

Contudo, a ideia de que a literatura e a sociedade estão de fato interligadas de modo complexo e intricado constitui, a esta altura, um quase-truísmo, que críticos diversos interpretam de inúmeras maneiras. Do mesmo modo, difundiu-se por toda parte a noção de que mesmo a obra mais deliberadamente pós-moderna da literatura brasileira há de propor questões espinhosas quanto à justiça e à injustiça. Afirmar que tais ideias se originaram com Antonio Candido ou são peculiares a sua obra seria grosseiramente impreciso. Ao mesmo tempo, minimizar o papel de Candido na articulação e disseminação de tais ideias num momento singularmente importante da história do país seria igualmente míope.

Mais para o fim de sua "Notícia da atual literatura brasileira: Instinto de nacionalidade", publicada originalmente em 1873, Machado de Assis afirma que "o que se deve exigir do escritor antes de tudo é certo sentimento íntimo, que o torne homem do seu tempo e do seu país, ainda quando trate de assuntos remotos no tempo e no espaço". Machado prossegue, sublinhando a necessidade premente de se forjar uma tradição crítica digna da literatura que então nascia e esboçando o papel que caberia ao crítico nesse processo. Mas, a despeito da divisão do trabalho intelectual que o ensaio propõe, não há dúvida de que o 
crítico deve partilhar integralmente desse "sentimento íntimo", se quiser julgar com acerto uma dada obra literária. A fidelidade apaixonada a um Brasil sempre fluido, que flui como um perdurável rio bonito através de Parceiros e de todos os escritos de Antonio Candido, garante seu lugar no presente. Essa fidelidade é seu legado para um futuro que ele ajudou a conformar.

Tradução de Samuel Titan Jr. 